\title{
Rice Hypersensitive Induced Reaction Protein 1 (OsHIR1) associates with plasma membrane and triggers hypersensitive cell death
}

\author{
Liang Zhou', Ming-Yan Cheung ${ }^{1}$, Man-Wah Li', Yaping Fu², Zongxiu Sun², Sai-Ming Sun ${ }^{1}$, Hon-Ming Lam ${ }^{1 *}$
}

\begin{abstract}
Background: In plants, HIR (ㅂypersensitive Induced Reaction) proteins, members of the PID (Proliferation, lon and Death) superfamily, have been shown to play a part in the development of spontaneous hypersensitive response Tesions in leaves, in reaction to pathogen attacks. The levels of HIR proteins were shown to correlate with localized host cell deaths and defense responses in maize and barley. However, not much was known about the HIR proteins in rice. Since rice is an important cereal crop consumed by more than $50 \%$ of the populations in Asia and Africa, it is crucial to understand the mechanisms of disease responses in this plant. We previously identified the rice HIR1 (OsHIR1) as an interacting partner of the OsLRR1 (rice Leucine-Rich Repeat protein 1). Here we show that OsHIR1 triggers hypersensitive cell death and its localization to the plasma mémbrane is enhanced by OsLRR1.

Result: Through electron microscopy studies using wild type rice plants, OsHIR1 was found to mainly localize to the plasma membrane, with a minor portion localized to the tonoplast. Moreover, the plasma membrane localization of OsHIR1 was enhanced in transgenic rice plants overexpressing its interacting protein partner, OsLRR1. Co-localization of OsHIR1 and OsLRR1 to the plasma membrane was confirmed by double-labeling electron microscopy. Pathogen inoculation studies using transgenic Arabidopsis thaliana expressing either OsHIR1 or OsLRR1 showed that both transgenic lines exhibited increased resistance toward the bacterial pathogen Pseudomonas syringae pv. tomato DC3000. However, OsHIR1 transgenic plants produced more extensive spontaneous hypersensitive response lesions and contained lower titers of the invading pathogen, when compared to OsLRR1 transgenic plants.

Conclusion: The OsHIR1 protein is mainly localized to the plasma membrane, and its subcellular localization in that compartment is enhanced by OsLRR1. The expression of OsHIR1 may sensitize the plant so that it is more prone to $H R$ and hence can react more promptly to limit the invading pathogens' spread from the infection sites.
\end{abstract}

\section{Background}

In plants, there are no immune cells against invading pathogens. Nonetheless, they have evolved different strategies for defense $[1,2]$. The current model depicts that plants can recognize pathogen-associated molecular patterns (PAMPs) to trigger an immune response. If such a defense mechanism is compromised by effectors produced by the pathogens, host plants that possess resistance proteins which can recognize the effectors will still be able to trigger an immune response. Both PAMP-triggered and effector-triggered

\footnotetext{
* Correspondence: honming@cuhk.edu.hk

'State Key Laboratory of Agrobiotechnology and School of Life Sciences, The Chinese University of Hong Kong, Shatin, Hong Kong SAR, PR China Full list of author information is available at the end of the article
}

immunities may result in hypersensitive response (HR), which is characterized by the rapid and localized responses that lead to the generation of reactive oxygen species, cell wall fortification and a special form of programmed cell death (PCD), also known as hypersensitive cell death [3-5]. PCD is an important mechanism of removing unwanted cells in order to model or remodel newly-forming organs [6-8]. Stress-induced PCD in both plant and animal cells may involve the endomembrane system [9].

HR involves the expression of genes and the de novo synthesis of proteins that are part of several defense response signaling pathways $[4,10,11]$. HR-like lesions can be induced in the absence of pathogens by overexpressing defense-related genes $[4,12-14]$. These genes can be 
categorized into 4 classes: pathogen-derived genes, genes involved in defense signal transduction, killer genes, and general metabolism-perturbing genes [13]. Furthermore, plants exhibiting transgene-induced cell death are also resistant to pathogen infection by activating the defense signaling pathways $[11,13]$.

Hypersensitive Induced Reaction (HIR) proteins are a group of proteins involved in HR. They belong to the PID (Proliferation, Ion and Death) superfamily, whose members function in cell proliferation, ion channel regulation and cell death [15]. HIR protein expression in maize and barley is associated with localized host cell death and disease resistance responses [15,16]. Their genes are up-regulated in plant leaves during the development of spontaneous HR lesions [15-17].

Rice is an important cereal that provides calories to more than $50 \%$ of the Asian and African populations. However, rice production has suffered from various pathogenic attacks [1]. While HIR proteins from other cereals have been shown to be involved in defense responses $[15,16]$, the information on the HIR proteins in rice is very limited. We previously identified the rice HIR1 (OsHIR1) as the interacting partner of the rice Leucine-Rich Repeat protein 1 (OsLRR1) via yeast twohybrid and in vitro pull-down experiments [18]. OsLRR1 enters the endosomal pathway and its ectopic expression in transgenic Arabidopsis thaliana can enhance the host resistance toward the virulent pathogen Pseudomonas syringae pv. tomato (Pst) DC3000 [18].

In this study, we provide evidence to show that OsLRR1 enhances the plasma membrane localization of OsHIR1. We also demonstrate the involvement of OsHIR1 in triggering hypersensitive cell death and plant defense response using transgenic $A$. thaliana.

\section{Results}

OsHIR1 encodes a Band 7-domain protein which is upregulated upon pathogen challenge

OsHIR1 was identified as a putative interacting partner of OsLRR1 [18]. The OsHIR1 protein exhibits high similarity (from $84 \%$ to $96 \%$ identity) to homologues from dicots and monocots (Figure 1a), including maize (Zea mays) [15], barley (Hordeum vulgare subsp. Vulgare) [16], wheat (Triticum aestivum) [19], pepper (Capsicum spp.) [20], and A. thaliana [21,22]. For all the close homologues of OsHIR1, computational analysis [23,24] reveals a putative $\mathrm{N}$-myristoylation site at the $\mathrm{N}$-terminus, followed by a transmembrane domain that is embedded within a Band 7-domain, which covers most of the OsHIR1 protein (Figure 1b). In an unrooted phylogenetic tree (Figure 1c), HIR proteins can be further divided into two branches: dicots and monocots. Among HIR homologues from monocots, the OsHIR1 shares the highest similarity with the maize ZmHIR1 (96\% identity).
To show that OsHIR1 is related to the plant defense response, we investigated whether its gene expression is responsive to pathogen challenge. Northern and western blot analyses showed that both the mRNA and protein levels of OsHIR1 increased after the rice plant was inoculated with the pathogen Xoo LN44 (Figure 1d). On the other hand, no such change was observed after mock treatment (Figure 1d).

\section{Subcellular localization of OsHIR1 and the possible interaction with OsLRR1}

We previously reported that the OsHIR1 proteins were retained in the membrane-associated protein fraction and might be localized to the plasma membrane [18]. However, a more detailed electron microscopy analysis showed that a minor portion of OsHIR1 signals could also be found to the tonoplast (Figure 2a, lower left panel).

To study the possible effects of OsLRR1 on the subcellular localization of OsHIR1, we constructed transgenic rice lines overexpressing OsLRR1. A transgenic line that exhibited a high level of OsLRR1 gene expression was chosen for subsequent electron microscopy analysis (Figure $2 \mathrm{~b}$ ). Interestingly, in addition to the elevated level of OsLRR1 mRNA, the expression of the OsHIR1 gene in the OsLRR1 transgenic line was also enhanced (Figure 2b).

Immuno-gold electron microscopy studies showed that not only the signal density of the OsLRR1 proteins, but also that of the OsHIR1 proteins, in the plasma membrane, was increased in the OsLRR1 overexpressing line by at least two folds, when compared to the untransformed control (Figure 2c). On the other hand, there was no significant difference (Student's t-test, $p<0.05$ ) between the number of OsHIR1 signals in the tonoplast of the OsLRR1 overexpressing line and that in the untransformed control. These results indicated that OsLRR1 enhanced the plasma membrane localization of OsHIR1.

To further confirm the in vivo interaction between OsHIR1 and OsLRR1 in the plasma membrane, a double labeling experiment was performed using rabbit antiOsLRR1 antibodies and mouse anti-OsHIR1 antibodies. Secondary antibodies conjugated with gold particles of different sizes (6 $\mathrm{nm}$ anti-rabbit IgG and $15 \mathrm{~nm}$ antimouse IgG) were employed to distinguish between the two target proteins. Proximal occurrences of large and small gold particles were detected in the plasma membrane (Figure 2d), supporting the notion that OsLRR1 and OsHIR1 co-localized and interacted in the plasma membrane.

\section{Ectopic expression of the OsHIR1 can cause spontaneous hypersensitive response lesions in the leaves of transgenic $A$. thaliana}

To perform a rapid gain-of-function test of OsHIR1, transgenic $A$. thaliana plants ectopically expressing 
(a)

HvHIR1

TaHIR1

ZmHIR1

OSHIR1

CaHIR1

AtHIR1

HvHIR1

TaHIR1

ZmHIR1

OSHIR1

CaHIR1

AtHIR1

HvHIR1

TaHIR1

ZmHIR1

OSHIR1

CaHIR1

AtHIR1

HvHIR1

TaHIR1

ZmHIR1

OSHIR1

CaHIR1

AtHIR1

HvHIR1

TaHIR1

ZmHIR1

OSHIR1

CaHIR1

AtHIR1

\begin{abstract}
$\mathrm{N}$-myristoylation site
$\downarrow$

MGGVLGLIQIDQSTVAIRETFGKFDAIIQPGCHCLPWCLGQQVAGYLSIRVQQIDVRCET 60 MGGVLGIIOI OSTVAIKETFGKFDAIT QPGCHCIPWCIGOOIAGYIST RVOQIDVRCET 60 MGQALGLIQVDQSTVAIKETFGKFDEVIEPGCHFLPWCIGRQIAGYLSI RVQQLDVRCET 60 MGQALGLIQV
MGQALGLVQVD STIVAIKESFGKFDEVI EPGCHFLPWCIGKQIAGYLSIRVQQLDVRCET 60 MGNLFCCVQV PSTVAIKEQFGKYRDVI EPGCHCVPWFLGSQLAGHLSIRVQQLDVRCET 60 MGNLFCCVQVDQSTVAIKETFGKFEDVIEPGCHFLPWCLGSQVAGYLSI RVQQLDVRCET 60
\end{abstract}

KTKDNVFVNVVASVQYRALADKASDAFYRLSNTREQIQSYVFDVIRASVPKMNLDDVFEQ 120 KTKDNVFVNVVASVQYRALADKASDAFYRLSNTREQIQSYVFDVIRASVPKMNLDDVFEQ 120 KTRDNVFVNVVASVQYRALADKASDAFYRLSNTREQIQSYVFDVIRASVPKMNLDDAFEQ 120 KTKDNVFVNVVASVOYRALAEKASDAFYRLSNTREOIOSYVFDVIRASVPKMNLDDAFEQ 120 KTKDNVFVNVVASIQYRALADKANEAFYKLSNTKGQIQAYVFDVIRASVPKLNLDDVFEQ 120 KTRDNVFVNVVASIQYRALANKANDAYYKLSNTRGQIQAYVFDVIRASVPKLLIDDVFEQ 120

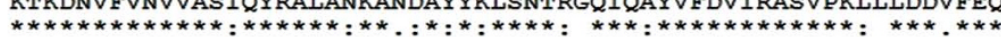

KNEIARAVEEELERAMSAYGYEIVQTLIVDIEPDEHVRRAMNEINAAARMRLAATERAEA 180 KNEIARAVEDELERAMSAYGYEIVQTLIVDIEPDEHVRRAMNEINAAARMRLAATEKAEA 180 KNEIARAVENELEKAMSMYGYEIVQTLIVDIEPDEHVRRAMNEINAAARLRLAASEKAEA 180 KNEIAKAVEDELEKAMSTYGYEIVQTLIVDIEPDEHVKRAMNEINAAARLRVAANEKAEA 180 KNEIAKSVEEELEKAMSAYGYEIVQTLIVDIVPDEHVRRAMNEINAAARLRVAANERAEA 180 KNDIARAVEEELEKAMSAYGYEIVQTLIVDIEPDEHVRRAMNEINAAARMRLAANEKAEA 180

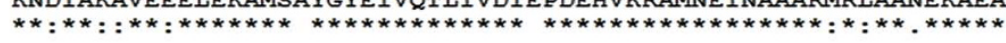

EKILOIKRAEGEAESKYLAGVGIAROROAIVDGLRDSVLAFSENVPGTSSKDVMDMVLVT 240 EKILQIKRAEGEAESKYLAGVGIARQROAIVDGLRDSVLAFSENVPGTSSKDVMDMVIVT 240 EKILQIKRAEGDAESKYLAGLGIARQRQAIVDGLRDSVLAFSENVPGTSAKDVMDMVLVT 240 EKILQIKRAEGDAESKYLAGLGIARQRQAIVDGLRDSVLAFSENVPGTSAKDVMDMVIVT 240 EKILQIKRAEGEAESKYLSGLGIARQRQAIVDGLRDSVLGFSVNVPGTTAKDVMDMVLVT 240 EKILQIKRAEGEAESKYLSGLGIARQRQAIVDGLRDSVLGFAVNVPGTTAKDVMDMVIVT 240 $* * * * * * * * * * *: * * * * * *: *: * * * * * * * * * * * * * * * * * * . *: ; * * * * *:: * * * * * * * * * *$

QYFDTMKDIGASSKSSAVFIPHGPGAVKDIASQIRDGQLQGRMV-- 284 QYFDTMKDIGASSKSSAVFI PHGPGAVRDIASQIRDGQIQGRMV-- 284 QYFDTMKEIGASSKSSSVFIPHGPGAVRDIAAQIRDGQLQASIL-- 284 QYFDTMKEIGASSKSSSVFIPHGPGAVKDIAAQIRDGQIQAKLI-- 284 QYFDTMKEIGAASKSSAVFI PHGPGAVKNVAQQIRDGLIQASVGH- 285 QYFDTMKEIGASSKSSAVFIPHGPGAVRDVASQIRDGLIQGSSANL 286

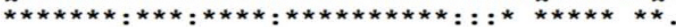

(b)

N-myristoylation site Putative TM

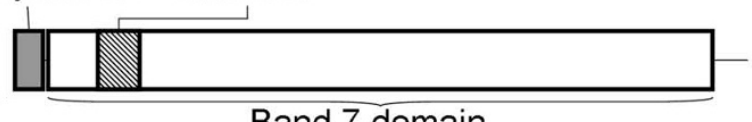

Band 7 domain

(d)

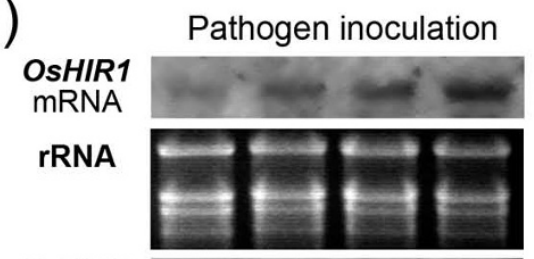

OsHIR1

protein

Total protein

Day

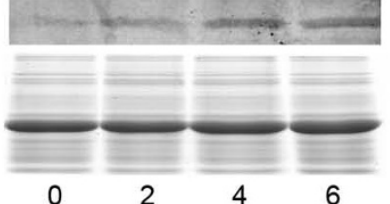

Mock treatment
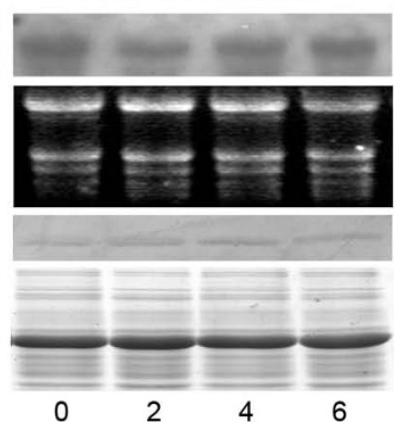

6
(C)

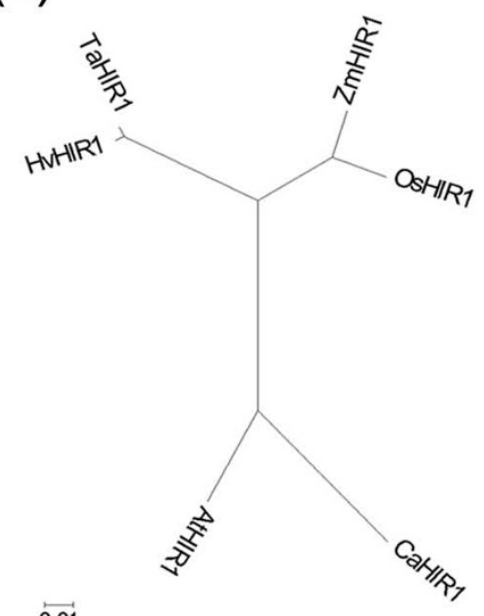

$\overleftrightarrow{0.01}$

Figure 1 Structural domains and phylogenetic relationships of OsHIR1 homologues and expression of OsHIR1 under pathogen inoculation. (a) Alignment of OsHIR1 homologues in plants. "**" represents conserved amino acid residues, ":" conserved substitutions, and "." semi-conserved amino acid substitutions. (b) Schematic representation of the conserved structural domains in OsHIR1 and its homologues. (c) Phylogenetic analysis of OsHIR1 and its published plant homologues. (d) The mRNA and protein levels of OsHIR1 0, 2, 4 and 6 days after inoculation of Xanthomonas oryzae pv. oryzae (XoO) race LN44 or mock treatment by a leaf-clipping method. Ten $\mu \mathrm{g}$ total RNA and $10 \mu \mathrm{g}$ total protein were loaded onto each lane. 


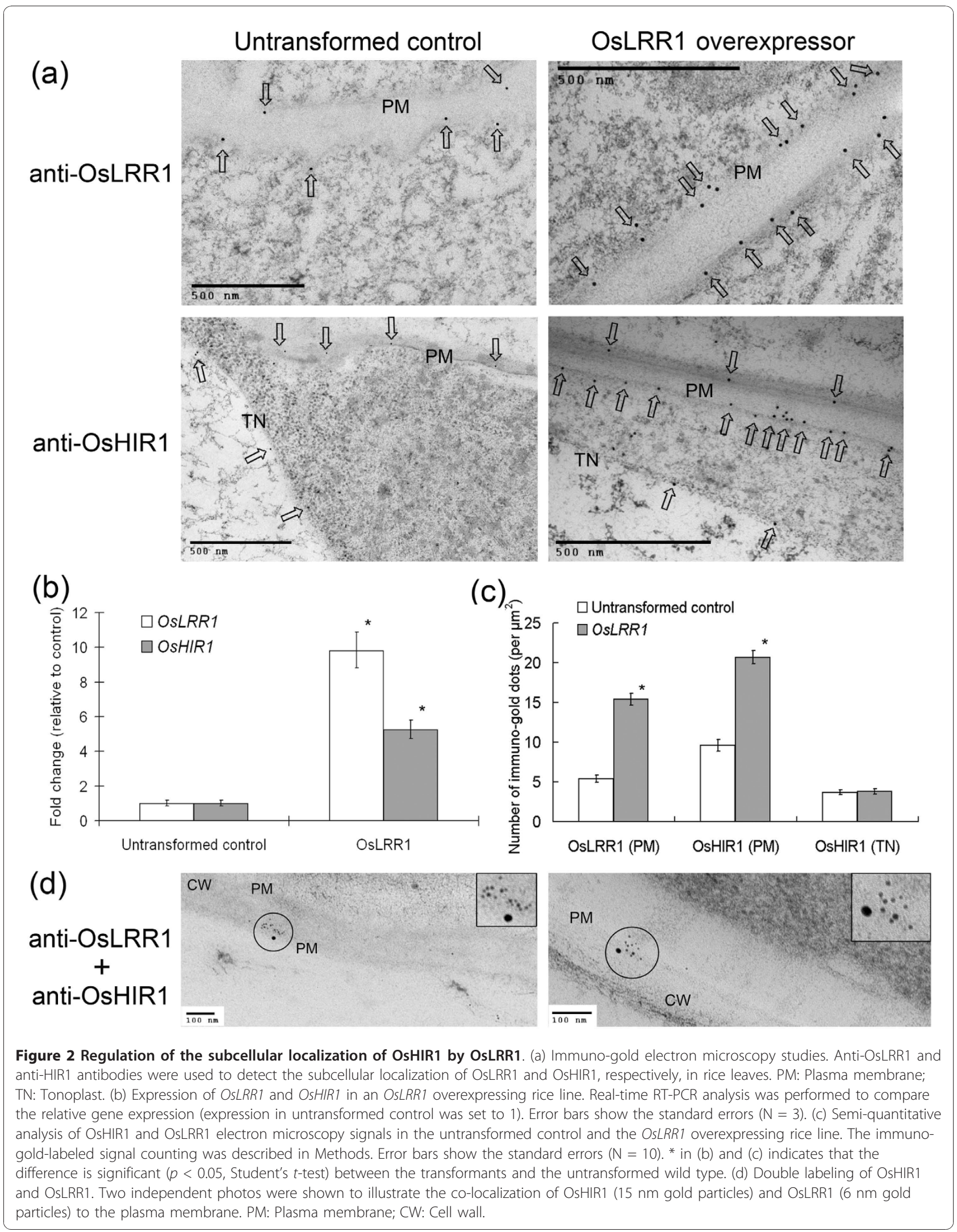


OsHIR1 were generated. Three weeks after germination, the leaves of about $20 \%$ of the OsHIR 1 transgenic plants (Col-0/OsHIR1) exhibited white spontaneous HR lesions located randomly at the margins and tips (Figure 3a, red arrows). As negative controls, the untransformed wild type (Col-0) and transgenic plants with the empty vector (Col-0/V7) exhibited normal growth. Transgenic plants expressing OsLRR1 (Col-0/OsLRR1) did not exhibit visible differences in the size, shape, or color of the leaves, when compared to the negative controls (Figure 3a).

To further observe the effect of OsHIR1 on cell death, lactophenol-trypan blue staining was performed using the leaves of the transgenic A. thaliana. The expression of OsHIR1 caused extensive spontaneous cell death (Figure 3b, black arrows). On the other hand, the expression of OsLRR1 only resulted in very mild spontaneous cell death (Figure $3 \mathrm{~b}$ ). This explains the lack of visible lesions found in OsLRR1 transgenic plants (Figure 3a). No spontaneous cell death was observed in the untransformed control and transgenic plants containing the empty vector (Figure $3 \mathrm{~b}$ ).

\section{Ectopic expression of OsHIR1 in transgenic $A$. thaliana} enhances resistance to $P$. syringae pv. tomato $D C 3000$ (Pst DC3000)

Previous studies indicated that the ectopic expression of OsLRR1, the interacting protein partner of OsHIR1, can enhance resistance toward bacterial pathogens in transgenic $A$. thaliana [18]. Using a similar experimental approach, we tested the effects of OsHIR1 in A. thaliana on the Pst DC3000-induced disease. Since OsHIR1 transgenic plants exhibiting extensive spontaneous HR responses under normal growth conditions would eventually die, we chose those individual plants that exhibited the mildest spontaneous HR responses for the subsequent pathogen inoculation tests. The expression of OsHIR1 in these plants was confirmed by RT-PCR (data not shown).

When the untransformed wild type (Col-0) or A. thaliana transformed with the empty vector cassette (Col-0/ V7) was inoculated with the pathogen Pst DC3000, disease symptoms (yellowing and necrosis) gradually appeared and the infected areas spread out from the original inoculation sites (Figure 4a). Such symptoms were alleviated in the transgenic line expressing OsLRR1, consistent with the results of our previous study [18]. The spread of pathogen infection was also suppressed by the ectopic expression of OsHIR1 (Figure 4a). Consistent with these visible symptoms, transgenic plants expressing either OsLRR1 or OsHIR1 exhibited a lower titer of pathogens when compared to Col-0 and the empty vector control (Figure 4b). However, the OsHIR1 transgenic lines showed a stronger effect on lowering the pathogen titer when compared to the OsLRR1 transgenic line (Figure 4b).

The expression levels of $P R 1$ and $P R 2$, two defense marker genes in the salicyclic acid pathway related to the defense against biotrophic pathogens such as Pst DC3000 [25], were monitored in both mock- (Figure 4c) (a)

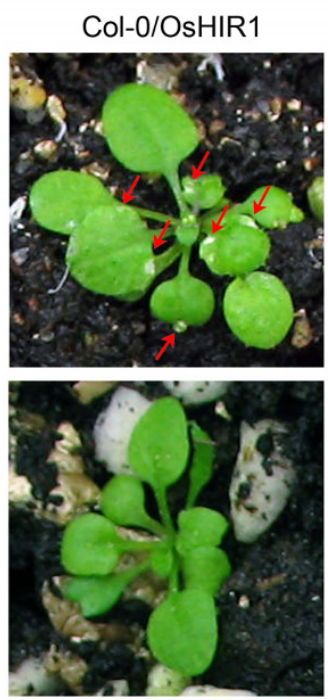

Col-0/OsLRR1
Col-0
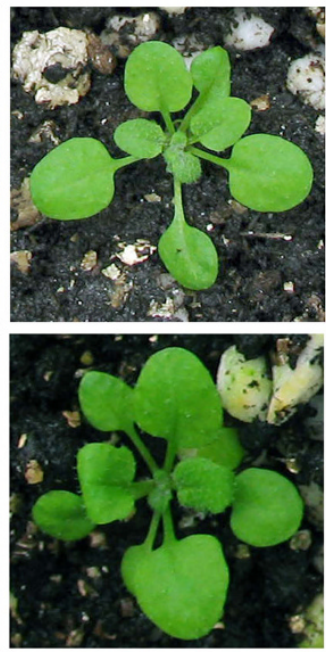

Col-0/V7

(b)

Col-0/OsHIR1
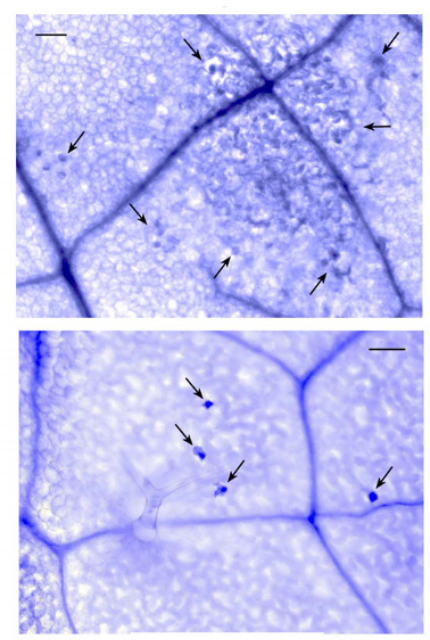

Col-0/OsLRR1

\section{Col-0}

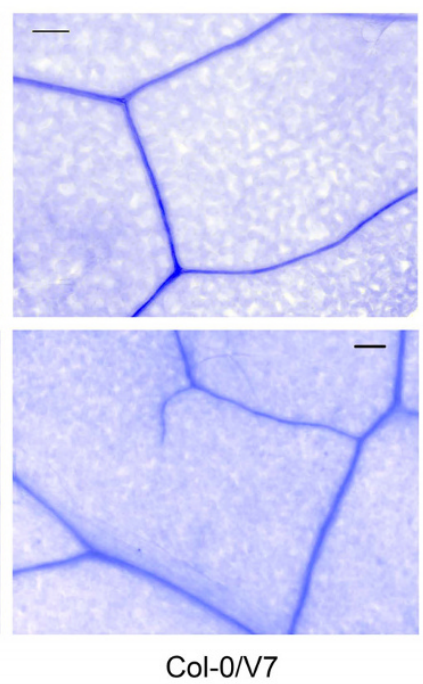

Figure 3 Hypersensitive response lesions and spontaneous cell death due to the overexpression of OsHIR1. (a) Hypersensitive response lesions in some OsHIR1 transgenic plants. Three weeks after germination, white necrotic lesions located randomly at the margins and tips of leaves (red arrows) were observed in about $20 \%$ of the OsHIR1 transgenic plants. Such a phenomenon was not found in untransformed wild type (Col-0), empty vector transgenic control (Col-0/N7), or OsLRR1 transgenic plants (Col-O/OsLRR1). (b) Lactophenol-trypan blue staining showing spontaneous cell death. Leaves of 3-week-old plants were stained with lactophenol-trypan blue to detect dead cells. Spontaneous cell death found on the leaves of OsHIR1 and OsLRR1 transgenic plants were indicated by black arrows. Bars $=100 \mu \mathrm{m}$ 


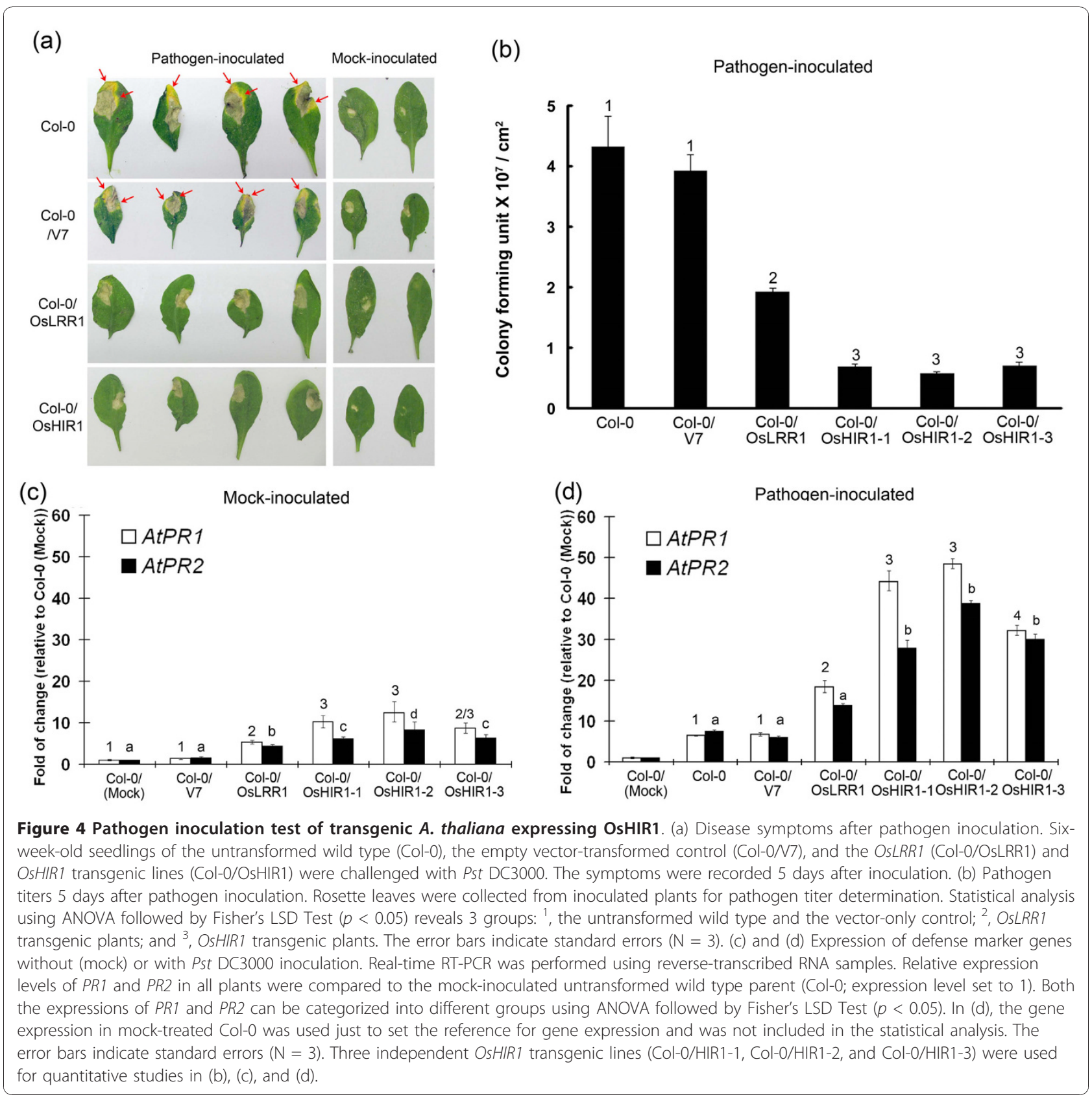

and pathogen-inoculated (Figure 4d) plants. In both mock-treated and pathogen-inoculated plants, the expression levels of $P R 1$ and $P R 2$ were elevated in both OsHIR1 and OsLRR1 transgenic plants when compared to Col-0 and transgenic plants containing the empty vector cassette. However, the OsHIR1 transgenic plants exhibited significantly higher levels of $P R 1$ and $P R 2$ gene induction than the OsLRR1 transgenic plants $(p<0.05)$.

\section{Discussion}

OsHIR1 is a member of the Band 7-domain-containing proteins (Figure 1). Many of these proteins are lipid raft-associated and may cluster to form membrane micro-domains, and in turn recruit multi-protein complexes functioning in membrane trafficking and signal transduction [26]. Signaling components found in plasma membrane lipid rafts may play important roles in defense responses. For example, an E3 ubiquitin ligase, RING1, is induced by pathogen infection, localizes to plasma membrane lipid rafts, and can trigger programmed cell death in A. thaliana [27].

Here the membrane localization of OsHIR1 was confirmed with electron microscopy studies (Figure 2). We also showed that OsHIR1 and OsLRR1 co-localized to 
the plasma membrane (Figure 2), possibly via lipid rafts. This result further confirms the tight interaction between OsHIR1 and OsLRR1 previously shown by yeast two-hybrid and in vitro pull-down assays [18]. Overexpressing OsLRR1 can induce the expression of OsHIR1 gene and can increase the portion of OsHIR1 localized to the plasma membrane (Figure 2). Therefore, it is likely that the function of OsHIR1 is regulated by its interacting partner OsLRR1.

It is an interesting observation that a minor portion of OsHIR1 is localized to the tonoplast (Figure 2). Although it has not been explicitly discussed in previous researches, proteomics studies have identified rice and Arabidopsis HIR1 homologues in both the plasma membrane and vacuole protein fractions [21,22,28-31]. A recent report showed that the vacuolar contents discharged and accumulated in the extracellular space could induce hypersensitive cell death [32]. However, the biological significance of the tonoplast localization of OsHIR1 remains unclear at this point.

OsLRR1 is a positive signaling component of plant defense responses [18]. The regulatory actions of OsLRR1 on the expression and localization of OsHIR1 suggest that OsHIR1 may be downstream of OsLRR1 in a defense response pathway. Previous studies of HIR1 homologues from maize, barley, and pepper indicated that they are associated with $\mathrm{HR}$ and disease resistance $[15,16,20]$.

In transgenic $A$. thaliana ectopically expressing OsHIR1, a portion of plants underwent uncontrolled spontaneous HR (Figure 3) and eventually died. OsHIR1 transgenic plants with the mildest spontaneous HR phenotype could survive and were more resistant to the bacterial pathogen Pst DC3000. The protective effects of OsHIR1 included the alleviation of disease symptoms, the lowering of pathogen titers, and the increased expression of defense marker genes. Similar effects could be obtained by expressing OsLRR1, the interacting protein partner of OsHIR1 [18] (Figure 4). In general, OsHIR1 showed a stronger enhancing effect on disease resistance when compared to OsLRR1. In the native system, OsLRR1, which is trafficked in the endosomal pathway, may participate in the surveillance of pathogen-related signals and then induce the production and regulate the plasma membrane localization of OsHIR1. It is likely that the protective function of OsLRR1 is at least in part mediated through OsHIR1.

\section{Conclusion}

The OsHIR1 protein identified in rice is mainly localized to the plasma membrane where it may co-localize and interact with the OsLRR1 protein. The overexpression of OsLRR1 can enhance the plasma membrane localization of OsHIR1. Ectopic expression of either OsHIR1 or OsLRR1 can cause spontaneous hypersensitive cell death and increased resistance toward bacterial pathogens, with OsHIR1 demonstrating a more pronounced effect than OsLRR1. We speculate that the expression of OsHIR1 may sensitize the plant so that it is more prone to HR and hence can react more promptly to restrict the spread of the invading pathogens from the infection sites. OsLRR1 may act as a regulator for the functions of OsHIR1.

\section{Methods}

Plant materials, chemicals, reagents and primers

A. thaliana wild-type Col-0 and Oryza sativa cultivar SN1033 are laboratory stocks. The Pseudomonas syringae pv. tomato DC3000 (Pst DC3000) was a gift from Dr. C. Lo (HKU). Enzymes and reagents for molecular studies were from Applied Biosystems (Foster City, CA), Clontech Laboratories, Inc. (Palo Alto, CA), Bio-Rad Laboratories (Hercules, CA), Promega Biosciences (San Luis Obispo, CA), and Roche Diagnostic Ltd (Basel, Switzerland). DNA oligos were from Integrated DNA Technologies, Inc. (Coraliville, IA), Invitrogen Corp. (Carlsbad, CA), and Tech Dragon Ltd. (Hong Kong). Chemicals for plant growth and tissue cultures were from Sigma-Aldrich Co. (St Louis, MO). The soil for A. thaliana cultivation was from Florgard Vertriebs GmbH (Gerhard-Stalling, Germany).

\section{RNA extraction, CDNA preparation, real-time PCR and northern blot analysis}

RNA extraction, cDNA preparation, and real-time PCR were performed as previously described [18,33-35]. For real-time PCR, at least two biological repeats were performed. All experiments were done with at least four technical replicates and at least three sets of consistent data were used for analysis. The expression levels of the A. thaliana UBQ10 gene (AtUBQ10; GenBank accession number AY139999; [36]) with the primer set 5'GGCCTTGTATAATCCCTGATGAATAAG-3' and 5'AAAGAGATAACAGGAACGGAAACATAGT-3' and the $O$. sativa $U B Q 5$ gene (OsUBQ5; GenBank accession number AK061988; [37]) with the primer set 5'ACCACTTCGACCGCCACTACT-3' and 5'-ACGCCTAAGCCTGCTGGTT-3' were used for normalization in A. thaliana and O. sativa respectively. The relative gene expression was calculated using the $2^{-\Delta \Delta C T}$ method [38].

Other primer sets for real-time PCR studies include AtPR1: 5'-AACTACAACTACGCTGCGAACAC-3' and 5'-CTTCTCGTTCACATAATTCCCAC-3'; AtPR2: 5'CGCCCAGTCCACTGTTGATA-3' and 5'-ACCACGATTTCCAACGATCC-3'; and OsHIR1: 5'-CCCTGGT GCATAGGGAAGCA-3' and 5'-CGTCTG ATGCCTT CTCAGCAA-3'. 
Northern blot analyses were performed as described $[33,35]$ using antisense single-stranded DNA probes labeled with digoxygenin (DIG) (Roche, Germany) [39].

\section{Plant growth and pathogen inoculation}

Rice lines were grown on soil in a greenhouse under natural sunlight for 4 to 5 weeks. Pathogen inoculations were performed using Xanthomonas oryzae pv. oryzae (Xoo) race LN44 by a leaf-clipping method [34,40,41]. The same procedure was used for mock treatment except that the pathogen was replaced with water. The day 0 sample was collected before treatment. Other samples were collected at 2,4 , and 6 days after treatment at around the same time of day (between 08:00 and 10:00 am).

For pathogen inoculation tests in A. thaliana, seedlings were first grown on Murashige \& Skoog salt mixture agar plates for 2 weeks before being transferred to Floragard potting soil and cultivated in a growth chamber $\left(22-24^{\circ} \mathrm{C}\right.$; relative humidity $70-80 \%$; light intensity 80-120 $\mu \mathrm{E}$ on a $16 \mathrm{~h}$ light- $8 \mathrm{~h}$ dark cycle). Preparation of the Pst DC3000 culture, inoculation (by syringe infiltration of $0.1 \mathrm{ml}$ inoculums at a concentration of $10^{6}$ colony-forming unit/ml in $10 \mathrm{mM} \mathrm{MgSO}_{4}$ supplemented with $0.02 \%(\mathrm{v} / \mathrm{v})$ Silwet L-77), and subsequent pathogen titer determination at 5 days post-inoculation were performed as previously described [42]. For the pathogen titer measurement, leaf discs were macerated and extracted with $10 \mathrm{mM} \mathrm{MgSO}_{4}$, and the results were obtained from plate counting [42]. Error bars are standard errors of the pathogen titer calculated from samples collected from 3 individual plants each consists of 3 leaf discs.

\section{Transgenic plant construction}

To construct transgenic rice lines overexpressing OsLRR1, the full-length coding region of OsLRR1 was subcloned into the binary vector pSB130 [43], using the primer set 5' - CCGAATTCATGGGGGCGGGGGCG CTG-3' and 5'-CAGGTCGACGCTAGCAGTTGGTGTCATATACAG-3'. Constitutive expression was driven by the Zea mays ubiquitin promoter [44]. The recombinant construct was introduced into the japonica rice SN1033 via an Agrobacterium-mediated protocol [45,46] using the A. tumefaciens strain EHA105.

Transgenic A. thaliana expressing OsLRR1 was from our previous work [18]. To construct transgenic $A$. thaliana expressing OsHIR1, a cDNA clone containing the full-length coding region was inserted into a binary vector (V7; [47]) and placed under the control of the cauliflower mosaic virus $35 \mathrm{~S}$ promoter using the primer set 5'-AGTTCTAGAATGGGTCAAGCACTCGGTT TGGTAC-3' and 5'-AAAAATCTA GATTAGATCAA TTTGGCCTGGAGCTG-3'. Agrobacterium-mediated transformation of A. thaliana was done as described previously [48]. T3 homozygous lines carrying a single insertion locus were used in this study.

\section{Electron microscopy studies}

For single labeling experiments, the embedding, sectioning, and immunolabeling steps were performed as described $[18,49]$ using mouse anti-OsHIR1 serum or rabbit anti-OsLRR1 serum [18]. All the sections were captured by formvar-coated 100 mesh hex nickel grid (Cat. No. G100H-Ni, Electron Microscopy Sciences). The subcellular localization of targeted proteins were subsequently detected by gold-labeled secondary antibodies (1:50 in 1\% PBS-BSA) against mouse (EMS25173) or rabbit (EMS25109) IgGs. Aqueous uranyl acetate/lead citrate post-stained sections were examined with the Hitachi H-7650 transmission electron microscope operating at $80 \mathrm{kV}$. Background signals were monitored by negative control experiments without the application of the primary antibodies [18]. All images were captured at regions showing clear plasma membrane and tonoplast, with the magnification between $50,000 \times$ to $80,000 \times$. At least ten randomly selected areas $\left(1-2 \mu \mathrm{m}^{2}\right)$ per section were used for counting the density of immuno-goldlabeled dots (number of dots per $\mu \mathrm{m}^{2}$ ) for statistical analysis.

For double labeling experiments, tissues were collected from the untransformed control. Sample preparation, labeling, post-staining, and detection procedures were the same as in single labeling experiments, except that rabbit anti-OsLRR1 serum and mouse anti-OsHIR1 serum (both 1:50 in 1\% PBS-BSA) were applied simultaneously to the sample grid to detect the target proteins. Goat anti-rabbit IgG (6 nm gold particle: EMS 25104) and goat anti-mouse IgG + IgM (15 nm gold particle: EMS 25173) were applied simultaneously to detect the primary antibodies.

\section{Western blot analysis}

Total proteins were extracted [49] and electrophoretically separated on an SDS-polyacrylamide gel (4\% stacking; $12.5 \%$ resolving) before being transferred to an activated polyvinylidene difluoride (PVDF) membrane pre-treated with absolute methanol for 5 min followed by protein transfer buffer for another $5 \mathrm{~min}$, using the Bio-Rad Mini Trans-Blot ${ }^{\circ}$ Electrophoretic Transfer Cell (170-3930; Bio-Rad). The blotting, blocking (with Western Breeze ${ }^{\mathrm{Tw}}$ blocking solution), and detection (using the Western Breeze ${ }^{\mathrm{Tm}}$ Immunodetection Kit; WB7106, Invitrogen) procedures were performed according to the manufacturer's manuals.

Primary antibodies against the OsHIR1 protein [18] were used. Anti-mouse secondary antibodies conjugated to an alkaline phosphatase (provided in the Western 
Breeze $^{\text {tu }}$ Immunodetection Kit) were used for primary antibody recognition.

\section{Lactophenol-trypan blue staining}

Spontaneous cell death was detected using lactophenoltrypan blue staining as previously described [50].

\section{Bioinformatics analysis}

Alignment of amino acid sequences was done using the ClustalW2 program http://www.ebi.ac.uk/Tools/clustalw2/. The GenBank accession numbers of HIR1 homologues in this work are: rice OsHIR1 (accession no. NM_001068279), barley HvHIR1 (accession no. AY137511), wheat TaHIR1 (accession no. EF514209), maize ZmHIR1 (accession no. NM_001112153), pepper CaHIR1 (accession no. AY529867), and Arabidopsis AtHIR1 (accession no. NM_125669). The putative Nmyristoylation site was predicted by ScanProsite [23] and CSS-Palm 2.0 [24]. The putative transmembrane domain was predicted by TopPred [51].

\section{Statistical analysis}

Statistical analyses were performed using Statistical Package for Social Sciences v. 15.0.

\section{Acknowledgements}

We thank J. Chu for assistance in editing this manuscript and S.W. Tong for technical supports. C. Lo kindly provided the Pseudomonas syringae pv. tomato DC3000 strain. This work was supported by the Hong Kong RGC General Research Fund 467608 (to H.-M.L.), the Hong Kong UGC AoE Plant \& Agricultural Biotechnology Project AoE-B-07/09 and the SHARF Grant (to H.M.L. and S.S.-M.S.).

\section{Author details}

${ }^{1}$ State Key Laboratory of Agrobiotechnology and School of Life Sciences, The Chinese University of Hong Kong, Shatin, Hong Kong SAR, PR China. ${ }^{2}$ State key Laboratory of Rice Biology, China National Rice Research Institute, Hangzhou, Zhejiang, PR China.

\section{Authors' contributions}

ZL carried out most of the experimental works. MYC prepared the recombinant construct for making transgenic rice, rice RNA samples for gene expression studies, and performed EM studies with double labeling together with MWL. YF and ZS generated the transgenic rice lines. HML coordinated the design, data analysis, and execution of this study. SMS participated in the experimental design. HML, ZL, MYC, and MWL wrote the manuscript. All authors read and approved the final manuscript.

Received: 12 October 2010 Accepted: 30 December 2010 Published: 30 December 2010

\section{References}

1. Jones JDG, Dangl JL: The plant immune system. Nature 2006, 444:323-329.

2. Pieterse CMJ, Leon-Reyes A, Van der Ent S, Van Wees SCM: Networking by small-molecule hormones in plant immunity. Nat Chem Biol 2009, 5:308-316.

3. Greenberg JT: Programmed cell death in plant-pathogen interactions. Ann Rev Plant Physiol Plant Mol Biol 1997, 48:525-545.

4. Greenberg JT, Yao N: The role and regulation of programmed cell death in plant-pathogen interactions. Cell Microbiol 2004, 6:201-211.

5. van Doorn WG, Woltering EJ: Many ways to exit? Cell death categories in plants. Trends Plant Sci 2005, 10:117-122.
6. Giuliani C, Consonni G, Gavazzi G, Colombo M, Dolfini S: Programmed cell death during embryogenesis in maize. Ann Bot 2002, 90:287-292.

7. Gunawardena AH, Greenwood JS, Dengler NG: Programmed cell death remodels lace plant leaf shape during development. Plant Cell 2004, 16:60-73.

8. Xu Y, Hanson MR: Programmed cell death during pollination-induced petal senescence in petunia. Plant Physiol 2000, 122:1323-1334.

9. Cacas JL: Devil inside: does plant programmed cell death involve the endomembrane system? Plant Cell Environ 2010, 33:1453-1473.

10. Jwa NS, Park SG, Park CH, Kim SO, Ahn IP, Park SY, Yoon CH, Lee YH: Cloning and expression of a rice CDNA encoding a Lls1 homologue of maize. Plant Pathol J 2000, 16:151-155.

11. Chung E, Oh SK, Park JM, Choi D: Expression and promoter analyses of pepper CaCDPK4 (Capsicum annuum calcium dependent protein kinase 4) during plant defense response to incompatible pathogen. Plant Pathol J 2007, 23:76-89

12. Zhou J, Loh Y, Bressan R, Martin G: The tomato gene Pti1 encodes a serine/threonine kinase that is phosphorylated by Pto and is involved in the hypersensitive response. Cell 1995, 83:925-935.

13. Mittler R, Rizhsky L: Transgene-induced lesion mimic. Plant Mol Biol 2000, 44:335-344.

14. Vailleau F, Daniel X, Tronchet M, Montillet $\mathrm{L}$, Triantaphylidès C, Roby D: A R2R3-MYB gene, AtMYB30, acts as a positive regulator of the hypersensitive cell death program in plants in response to pathogen attack. Proc Natl Acad Sci USA 2002, 99:10179-10184.

15. Nadimpalli R, Yalpani N, Johal GS, Simmons CR: Prohibitins, stomatins, and plant disease response genes compose a protein superfamily that controls cell proliferation, ion channel regulation, and death. $J$ Biol Chem 2000, 275:29579-29586.

16. Rostoks N, Schmierer D, Kudrna D, Kleinhofs A: Barley putative hypersensitive induced reaction genes: genetic mapping, sequence analyses and differential expression in disease lesion mimic mutants. Theor Appl Genet 2003, 107:1094-1101.

17. Xiao F, Tang X, Zhou JM: Expression of 35S::: Pto globally activates defense-related genes in tomato plants. Plant Physiol 2001, 126:1637-1645.

18. Zhou L, Cheung MY, Zhang Q, Lei CL, Zhang SH, Sun SSM, Lam HM: A novel simple extracellular leucine-rich repeat (eLRR) domain protein from rice (OsLRR1) enters the endosomal pathway and interacts with the hypersensitive-induced reaction protein 1 (OsHIR1). Plant Cell Environ 2009, 32:1804-1820.

19. Yu XM, Yu XD, Qu ZP, Huang XJ, Guo J, Han QM, Zhao J, Huang LL, Kang ZS: Cloning of a putative hypersensitive induced reaction gene from wheat infected by stripe rust fungus. Gene 2008, 407:193-198.

20. Jung HW, Hwang BK: The leucine-rich repeat (LRR) protein, CaLRR1, interacts with the hypersensitive induced reaction (HIR) protein, CaHIR1, and suppresses cell death induced by the CaHIR1 protein. Mol Plant Pathol 2007, 8:503-514.

21. Jaquinod M, Villiers F, Kieffer-Jaquinod S, Hugouvieux V, Bruley C, Garin J, Bourguignon J: A proteomics dissection of Arabidopsis thaliana vacuoles isolated from cell culture. Mol Cell Proteomics 2007, 6:394-412.

22. Carter C, Pan S, Zouhar J, Avila EL, Girke T, Raikhel NV: The vegetative vacuole proteome of Arabidopsis thaliana reveals predicted and unexpected proteins. Plant Cell 2004, 16:3285-3303.

23. De Castro E, Sigrist CJA, Gattiker A, Bulliard V, Langendijk-Genevaux PS, Gasteiger E, Bairoch A, Hulo N: ScanProsite: detection of PROSITE signature matches and ProRule-associated functional and structural residues in proteins. Nucl Acids Res 2006, 34:W362-W365.

24. Ren J, Wen L, Gao X, Jin C, Xue Y, Yao X: CSS-Palm 2.0: an updated software for palmitoylation sites prediction. Protein Eng Des Sel 2008, 21:639-644.

25. Thomma BPHJ, Eggermont K, Penninckx IAMA, Mauch-Mani B, Vogelsang $R$, Cammue B, Broekaert WF: Separate jasmonate-dependent and salicylatedependent defense-response pathways in Arabidopsis are essential for resistance to distinct microbial pathogens. Proc Natl Acad Sci USA 1998, 95:15107-15111.

26. Browman DT, Hoegg MB, Robbins SM: The SPFH domain-containing proteins: more than lipid raft markers. Trends Cell Biol 2007, 17:394-402.

27. Lin SS, Martin R, Mongrand S, Vandenabeele S, Chen KC, Jang IC, Chua NH: RING1 E3 ligase localizes to plasma membrane lipid rafts to trigger FB1-induced programmed cell death in Arabidopsis. Plant J 2008, 56:550-561. 
28. Chen F, Yuan Y, Li Q, He Z: Proteomic analysis of rice plasma membrane reveals proteins involved in early defense response to bacterial blight. Proteomics 2007, 7:1529-1539.

29. Nohzadeh Malakshah S, Habibi Rezaei M, Heidari M, Hosseini Salekdeh G: Proteomics reveals new salt responsive proteins associated with rice plasma membrane. Biosci Biotechnol Biochem 2007, 71:2144-2154.

30. Natera SHA, Ford KL, Cassin AM, Patterson JH, Newbigin EJ, Bacic A Analysis of the Oryza sativa plasma membrane proteome using combined protein and peptide fractionation approaches in conjunction with mass spectrometry. J Proteome Res 2008, 7:1159-1187.

31. Marmagne A, Ferro M, Meinnel T, Bruley C, Kuhn L, Garin J, BarbierBrygoo $H$, Ephritikhine $\mathrm{G}$ : A high content in lipid-modified peripheral proteins and integral receptor kinases features in the Arabidopsis plasma membrane proteome. Mol Cell Proteomics 2007, 6:1980.

32. Hatsugai N, Iwasaki S, Tamura K, Kondo M, Fuji K, Ogasawara K, Nishimura M, Hara-Nishimura I: A novel membrane fusion-mediated plant immunity against bacterial pathogens. Genes Dev 2009, 23:2496-2506.

33. Ausubel FM, Brent R, Kingston RE, Moore DD, Seidman JG, Smith JA, Struhl K: Phenol/SDS method for plant RNA preparation John Wiley \& Sons Inc; 1995.

34. Cheung MY, Zeng NY, Tong SW, Li FWY, Zhao KJ, Zhang Q, Sun SSM, Lam HM: Expression of a RING-HC protein from rice improves resistance to Pseudomonas syringae pv. tomato DC3000 in transgenic Arabidopsis thaliana. J Exp Bot 2007, 58:4147-4159.

35. Sambrook J, Russell DW: Molecular Cloning: a Laboratory Manual Cold Spring Harbor: Cold Spring Harbor Laboratory Press; 2001.

36. Remans T, Smeets K, Opdenakker K, Mathijsen D, Vangronsveld J, Cuypers A: Normalisation of real-time RT-PCR gene expression measurements in Arabidopsis thaliana exposed to increased metal concentrations. Planta 2008, 227:1343-1349.

37. Jain M, Nijhawan A, Tyagi AK, Khurana JP: Validation of housekeeping genes as internal control for studying gene expression in rice by quantitative real-time PCR. Biochem Biophys Res Commun 2006, 345:646-651.

38. Livak KJ, Schmittgen TD: Analysis of relative gene expression data using real-time quantitative PCR and the 2(-Delta Delta C(T)) method. Methods 2001, 25:402-408.

39. Finckh U, Lingenfelter PA, Myerson D: Producing single-stranded DNA probes with the Taq DNA polymerase: a high yield protocol. BioTechniques 1991, 10:35-36, 38-39.

40. Cheung MY, Zeng NY, Tong SW, Li FWY, Xue Y, Zhao KJ, Wang C, Zhang Q Fu Y, Sun Z, et al: Constitutive expression of a rice GTPase-activating protein induces defense responses. New Phytol 2008, 179:530-545.

41. Zhang Q, Shi AN, Yang WC, Wang CL: Breeding of three near-isogenic Japonica rice lines with different major genes for resistance to bacterial blight. Acta Agronom Sin 1996, 22:135-141.

42. Katagiri F, Thilmony R, He SY: The Arabidopsis thaliana-Pseudomonas syringae interaction. In The Arabidopsis Book. Volume 39. Edited by: Somerville CR, Meyerowitz EM. Rockville, MD: American Society of Plant Biologists; 2002.

43. Yu HX, Liu QQ, Wang L, Zhao ZP, Xu L, Huang BL, Gong ZY, Tang SZ, Gu NH: Breeding of selectable marker-free transgenic rice lines containing AP1 gene with enhanced disease resistance. Sci Agric Sin 2006, 5:805-811.

44. Rooke L, Byrne D, Salgueiro S: Marker gene expression driven by the maize ubiquitin promoter in transgenic wheat. Ann Appl Biol 2000, 136:167-172

45. Hiei $Y$, Ohta $S$, Komari T, Kumashiro T: Efficient transformation of rice (Oryza sativa L.) mediated by Agrobacterium and sequence analysis of the boundaries of the T-DNA. Plant J 1994, 6:271-282.

46. Zhu L, Fu YP, Liu WZ, Hu GC, Si HM, Tang KX, Sun ZX: Rapidly obtaining the marker-free transgenic rice with three target genes by cotransformation an anther culture. Chin J Rice Sci 2007, 14:239-247.

47. Brears T, Liu C, Knight TJ, Coruzzi GM: Ectopic overexpression of asparagine synthetase in transgenic tobacco. Plant Physiol 1993, 103:1285-1290.

48. Bent AF: Arabidopsis in planta transformation. Uses, mechanisms, and prospects for transformation of other species. Plant Physiol 2000, 124:1540-1547

49. Lam SK, Siu CL, Hillmer S, Jang S, An G, Robinson DG, Jiang L: Rice SCAMP1 defines clathrin-coated, trans-Golgi-located tubular-vesicular structures as an early endosome in tobacco BY-2 cells. Plant Cell 2007, 19:296-319.

50. Koch E, Slusarenko A: Arabidopsis is susceptible to infection by a downy mildew fungus. Plant Cell 1990, 2:437-445.

51. Claros MG, Heijne G: TopPred II: an improved software for membrane protein structure predictions. Comp Appl Biosci 1994, 10:685-686.

\section{doi:10.1186/1471-2229-10-290}

Cite this article as: Zhou et al:: Rice Hypersensitive Induced Reaction Protein 1 (OsHIR1) associates with plasma membrane and triggers hypersensitive cell death. BMC Plant Biology 2010 10:290.

\section{Submit your next manuscript to BioMed Central and take full advantage of:}

- Convenient online submission

- Thorough peer review

- No space constraints or color figure charges

- Immediate publication on acceptance

- Inclusion in PubMed, CAS, Scopus and Google Scholar

- Research which is freely available for redistribution

Submit your manuscript at www.biomedcentral.com/submit
Biomed Central 